\title{
THE EFFECTS OF INDUCED FEVER ON CEREBRAL FUNCTIONS IN NEUROSYPHILIS
}

\author{
By ALBERT HEYMAN, JOHN L. PATTERSON, JR., AND FENWICK T. NICHOLS, JR. \\ (From the Departments of Medicine and Physiology, Emory University School of Medicine, \\ and the Clinic for Genito-infectious Diseases, Grady Memorial Hospital and the \\ Georgia Department of Public Health, Atlanta, Ga.)
}

(Submitted for publication, February 10, 1950; accepted, July 10, 1950)

Although fever is known to be associated with definite alterations in the circulation and metabolism of the body as a whole and of certain individual organs, there have been few observations on the changes occurring in the brain during fever. An increase in the cerebral arteriovenous oxygen difference was found in 15 patients with dementia paralytica during fever produced by typhoid vaccine and inductotherm (1). It was suggested that the brain in these patients either responded to fever with a rise in metabolism greater than other parts of the body or else the cerebral blood flow is slower during fever, thus accounting for a larger arteriovenous difference. Looney and Borkovic (2), however, found a slight decrease in the cerebral oxygen arteriovenous difference in 12 patients with dementia paralytica undergoing diathermic fever treatment, but they did not believe that these changes were significant. The oxygen consumption of brain tissue in vitro has been found to increase with temperature at levels lower than normal (3). At temperatures greater than normal, however, conflicting results have been obtained by different investigators $(3,4)$.

The present report presents studies on the effects of induced fever on the cerebral circulation and oxygen consumption in 27 patients with neurosyphilis.

\section{METHODS}

The control subjects and some of the patients with neurosyphilis in the present investigation were among those considered in a previous report in which the cerebral blood flow and oxygen consumption were determined before and after treatment for neurosyphilis (5). Fourteen of the patients in the present study had dementia paralytica and 13 had asymptomatic neurosyphilis. Fever was induced by the intravenous injection of typhoid bacterial pyrogen in all of the patients except two with dementia paralytica, who were inoculated with malarial parasites. The typhoid pyrogen employed was a suspension of heat-killed $E$. typhosa, containing approximately one billion organisms per cubic centimeter. The amount injected intravenously was $0.1 \mathrm{cc}$. This usually produced a chill followed by a rise in temperature to $101^{\circ} \mathrm{F} .-104^{\circ} \mathrm{F}$. Temperature measurements were made with a continuously-indicating rectal thermometer. Comparative cerebral blood flow determinations were made in each patient during normal temperature and during the flush phase of fever. These studies were carried out on the same day in seven patients and on different days in the remaining cases. The determinations were made at the height of the fever, usually four hours after the injection of the pyrogen. Care was taken to avoid making studies during or shortly after the chill phase. The interval between the administration of pyrogen and the cerebral blood flow studies was approximately the same in both groups of patients. In the two patients with malarial paroxysms the temperature began to rise three to four hours before the studies were made. The mean elevation of temperature in the patients with dementia paralytica was the same as in those with asymptomatic neurosyphilis and measured $3.9^{\circ} \mathrm{F}$. In most of the patients the cerebral blood flow studies were performed before the administration of either penicillin or fever therapy for neurosyphilis.

The clinical manifestations, spinal fluid findings and duration of neurosyphilis in the patients were generally the same as those of the patients considered in the preceding report (5). The patients with dementia paralytica had a mean age of 41 years, and those with asymptomatic neurosyphilis, 37 years.

The nitrous oxide method of Kety and Schmidt (6), with the slight modifications previously described (5), was used for the determination of cerebral blood flow (CBF). Cerebral oxygen consumption' $\left(\mathrm{CMRO}_{2}\right)$ was obtained from this value and the cerebral arteriovenous oxygen difference. The analyses of blood for nitrous oxide were done by the method of Orcutt and Waters (7), as modified by Kety and Schmidt, and analyses for carbon dioxide and oxygen were carried out separately by the manometric techniques given by Peters and Van Slyke (8). Mean arterial blood pressure was measured with a damped mercury manometer. Cerebral vascular resistance (CVR) was calculated by dividing the mean arterial pressure by the cerebral blood flow. The period of inhalation of nitrous oxide was increased to 14 minutes in most of the patients during fever in order to detect increased extracerebral contribution to the internal jugular blood. The fall in CBF between 10 and 14 minutes was not of such magnitude as to indicate excessive amounts of blood from extracerebral sources. 
TABLE I

Mean values and standard deviations in control subjects and in patients with neurosyphilis with normal temperatures and during fever

\begin{tabular}{|c|c|c|c|c|c|c|c|c|c|c|c|c|}
\hline & \multirow{2}{*}{\multicolumn{2}{|c|}{$\frac{\text { Control subjects }}{\text { Afebrile }}$}} & \multicolumn{5}{|c|}{ Asymptomatic neurosyphilis } & \multicolumn{5}{|c|}{ Dementia paralytica } \\
\hline & & & \multicolumn{2}{|c|}{ Afebrile } & \multicolumn{2}{|c|}{ During fever } & \multirow{2}{*}{\begin{tabular}{|l|} 
Change \\
Mean
\end{tabular}} & \multicolumn{2}{|c|}{ Afebrile } & \multicolumn{2}{|c|}{ During fever } & \multirow{2}{*}{\begin{tabular}{|l|} 
Change \\
Mean
\end{tabular}} \\
\hline & Mean & - & Mean & - & Mean & - & & Mean & $\cdot$ & Mean & - & \\
\hline Cerebral blood flow & 58 & \pm 7 & 57 & \pm 11 & 58 & \pm 13 & $2.3 \%$ & 39 & \pm 10 & 51 & \pm 9 & $30 \%$ \\
\hline Cerebral $\mathrm{O}_{2}$ consumption & 3.1 & \pm .4 & 3.0 & \pm .4 & 3.1 & \pm .6 & $3.3 \%$ & 2.1 & \pm .7 & 2.6 & \pm .6 & $24 \%$ \\
\hline $\begin{array}{l}\text { Cerebral vasc. resist. } \\
\mathrm{mm} . \mathrm{Ho} / \mathrm{cc} / 100 \mathrm{Gm} / \mathrm{min}\end{array}$ & 1.8 & \pm .4 & 2.1 & \pm .6 & 1.6 & \pm .5 & $24 \%$ & 2.6 & \pm .9 & 1.7 & \pm .3 & $35 \%$ \\
\hline $\begin{array}{l}\text { A-V oxygen difference } \\
\text { Volumes \% }\end{array}$ & 5.5 & \pm .9 & 5.5 & \pm .9 & 5.3 & \pm .8 & $4 \%$ & 5.4 & \pm 1 & 5.0 & \pm 3 & $7 \%$ \\
\hline $\begin{array}{l}\text { Respiratory quotient } \\
\text { Mean arterial blood } \\
\text { Pressure } \mathrm{mm} . \mathrm{Hg}\end{array}$ & $\begin{array}{l}1.06 \\
105\end{array}$ & $\begin{array}{l} \pm .2 \\
\pm 23\end{array}$ & $\begin{array}{l}0.9 \\
110\end{array}$ & $\begin{array}{l} \pm .15 \\
\pm 15\end{array}$ & $\begin{array}{l}1.0 \\
85\end{array}$ & $\begin{array}{l} \pm .05 \\
\pm 17\end{array}$ & $23 \%$ & $\begin{array}{l}1.1 \\
93\end{array}$ & $\begin{array}{l} \pm .3 \\
\pm 11\end{array}$ & $\begin{array}{l}1.0 \\
84\end{array}$ & $\begin{array}{l} \pm .2 \\
\pm 13\end{array}$ & $10 \%$ \\
\hline $\begin{array}{l}\text { Hematocrit } \\
\text { Temperature }{ }^{\circ} \mathrm{F} \text {. }\end{array}$ & 38 & \pm 4 & $\begin{array}{l}40 \\
99\end{array}$ & $\begin{array}{l} \pm 5 \\
\pm .6\end{array}$ & $\begin{array}{l}39 \\
102.9\end{array}$ & $\begin{array}{l} \pm 5 \\
\pm .8\end{array}$ & $1 \%$ & $\begin{array}{l}40 \\
98.7\end{array}$ & $\begin{array}{l} \pm 3 \\
\pm .6\end{array}$ & $\begin{array}{l}36 \\
102.6\end{array}$ & $\begin{array}{l} \pm 5 \\
\pm 1.4\end{array}$ & $7 \%$ \\
\hline
\end{tabular}

Significance of difference between afebrile and febrile means: Values of P: Asymptomatic neurosyphilis-CBF $>$

Dementia paralytica- $\quad$ CBF $<.02$

$\begin{array}{rlrl}\mathrm{CMRO}_{2}>.6 & \mathrm{CVR}>.02 \\ \mathrm{CMRO}_{2}>.05 & \mathrm{CVR}<.05 \\ <.1 & \end{array}$

\section{RESULTS}

The mean cerebral blood flow (CBF) in the patients with asymptomatic neurosyphilis when afebrile was $57 \mathrm{cc} . / 100 \mathrm{Gm}$. brain/min., a value almost identical with that of the control subjects (Table I). During fever the mean CBF in the patients with asymptomatic neurosyphilis remained practically unchanged (Figure 1). In contrast, the patients with dementia paralytica had the low $C B F$ value of $39 \mathrm{cc} / 100 \mathrm{Gm} . / \mathrm{min}$. before fever; this value increased in the febrile period and reached an average figure of $51 \mathrm{cc}$. $(\mathrm{p}<.02)$.

In general, the paretic patients with the greatest degree of mental deterioration showed the lowest blood flow values in the afebrile period and had the greatest increase with fever. Three patients with asymptomatic neurosyphilis of more than 10 years duration also had low $C B F$ values which increased during fever. This correlation between the level of the CBF in the afebrile period and the magnitude and direction of change with fever is shown in Figure 2. The patients with dementia paralytica had the lowest blood flow values and showed a rise with fever. The patients with asymptomatic neurosyphilis who had the highest values tended to show a fall with fever.
No correlation was found between the change in $\mathrm{CBF}$ and the degree of temperature elevation within the range of $101^{\circ} \mathrm{F}$. to $104^{\circ} \mathrm{F}$. observed in our patients. No information was obtained as to the effect of fever of long duration, since the studies were performed approximately four hours after injection of the pyrogen.

The mean arterial blood pressure fell in every patient during the period of fever. The average decrease was $23 \%$ in the patients with asymptomatic neurosyphilis and $10 \%$ in those with dementia paralytica. In the individual patients the change in blood flow from its afebrile value correlated poorly with the change in mean arterial pressure. In fact, a number of patients showed a rise in cerebral blood flow despite a fall in arterial pressure during fever.

Cerebral oxygen consumption. The mean cerebral oxygen consumption in the patients with asymptomatic neurosyphilis was normal in the afebrile state and showed almost no change during fever (Figure 3 ). The patients with dementia paralytica, however, had the subnormal mean $\mathrm{CMRO}_{2}$ value of $2.1 \mathrm{cc} . / 100 \mathrm{Gm} . / \mathrm{min}$. when afebrile. This value increased to $2.6 \mathrm{cc}$. during fever, a rise of $24 \%(.1>p>.05)$. This 


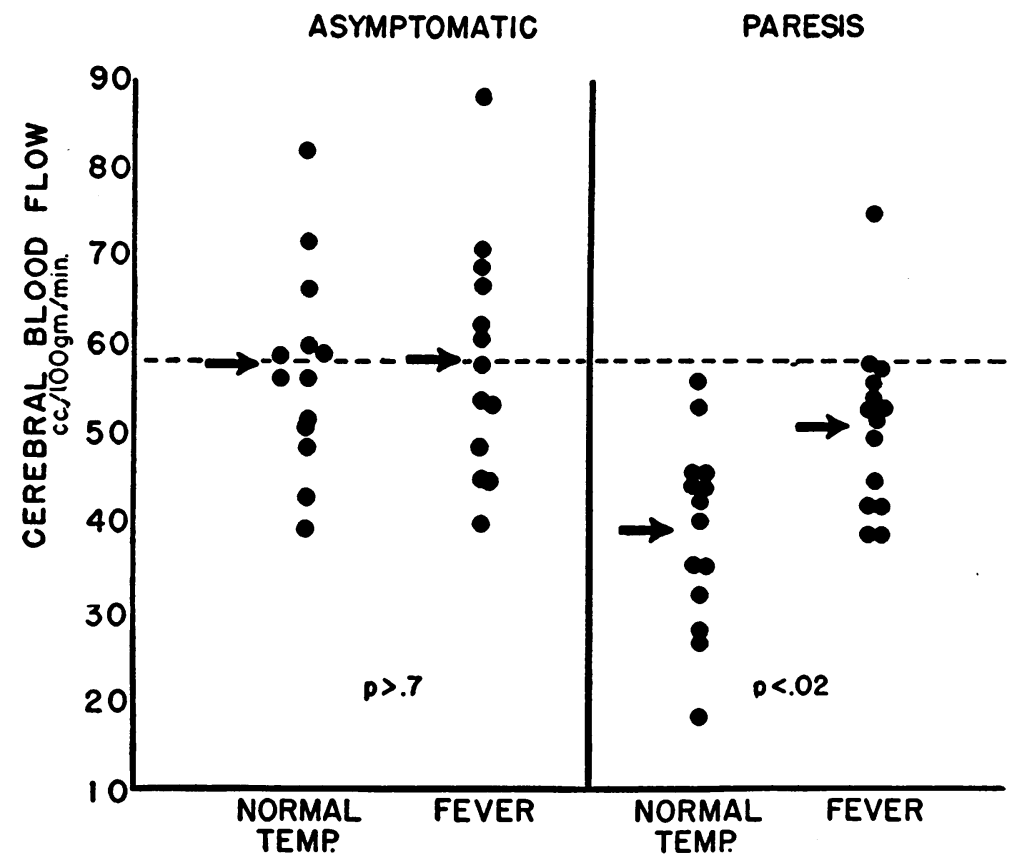

Fig. 1. Values for Cèrebral Blood Flow Obtained in the Individual

\section{Patients}

The arrows indicate the mean value in each group. The broken line indicates the mean value in control subjects with normal temperature.

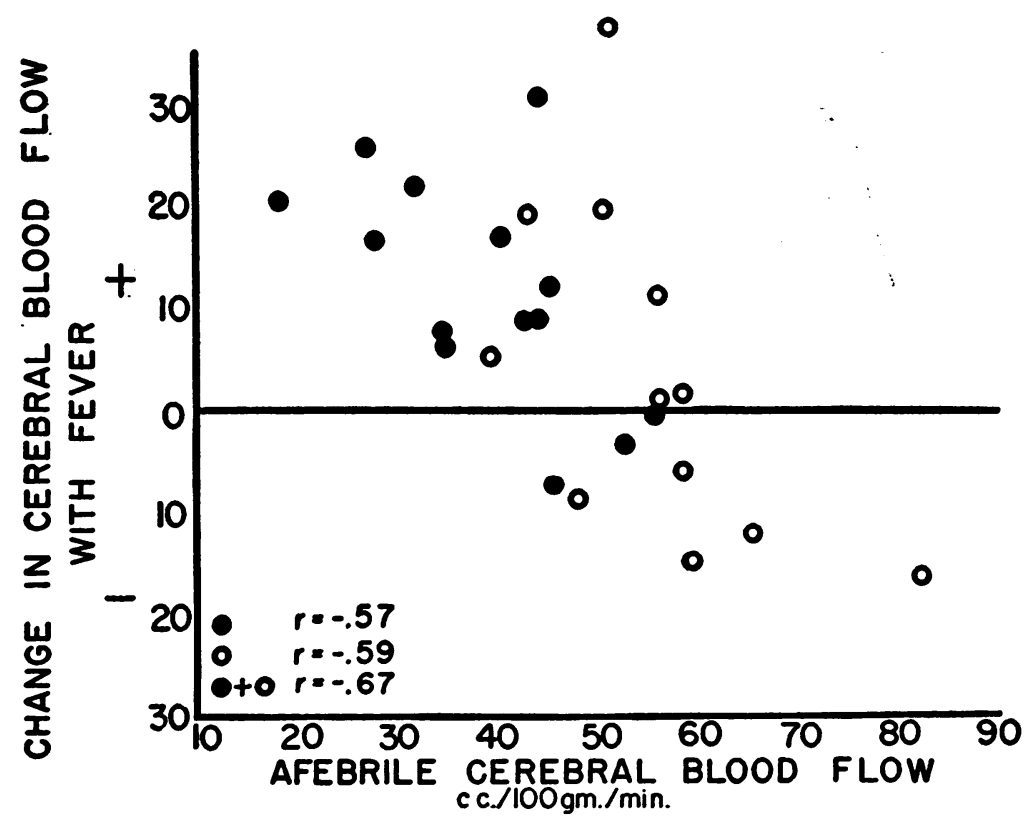

Fig. 2. Correlation Between the Cerebral Blood Flow in the Afebrile State and the Change in Flow During Fever

The solid dots represent patients with dementia paralytica; the circles, patients with asymptomatic neurosyphilis. 
represents an average rise of $6 \%$ per degree Fahrenheit.

Unlike the cerebral blood flow, the change in oxygen consumption in the individual patient during fever showed very poor correlation with the $\mathrm{CMRO}_{2}$ in the afebrile state. This was true in both groups of patients. There was, however, some tendency, particularly in the patients with dementia paralytica, for the change in oxygen consumption with fever to correlate with both the direction and magnitude of the change in blood flow.

The relationships between the values of the cerebral blood flow and oxygen consumption showed interesting differences in the two groups of patients (Figure 4). In the asymptomatic patients the correlation at normal body temperature was poor $(r=.48)$. During fever, however, a good correlation $(r=.84)$ was found between these functions. This re-alignment was brought about by changes in both flow and oxygen consumption in nearly every patient. The patients with dementia paralytica showed a fairly good cor- relation $(r=.72)$ between the $\mathrm{CBF}$ and $\mathrm{CMRO}_{2}$ in the afebrile state, but a somewhat poorer correlation during fever $(\mathrm{r}=.58)$.

Cerebral vascular resistance. The cerebral vascular resistance fell almost invariably in both groups of patients during fever. In asymptomatic neurosyphilis the mean CVR decreased by $24 \%$ $(.05>\mathrm{p}>.02)$, while in dementia paralytica there was a greater reduction, which amounted to $35 \%(\mathrm{p}<.01)$. There was a tendency for patients with higher CVR values to show the greater reductions with fever. No correlation was found in either group between the magnitude of the temperature rise and the fall in CVR.

\section{DISCUSSION}

The changes in the cerebral blood flow and oxygen consumption observed in our patients may represent responses either to the temperature elevation or to the pyrogen itself. Recent studies $(9,10)$ have shown that the administration of pyrogenic substances concomitantly with antipyretic drugs produces considerable increases in

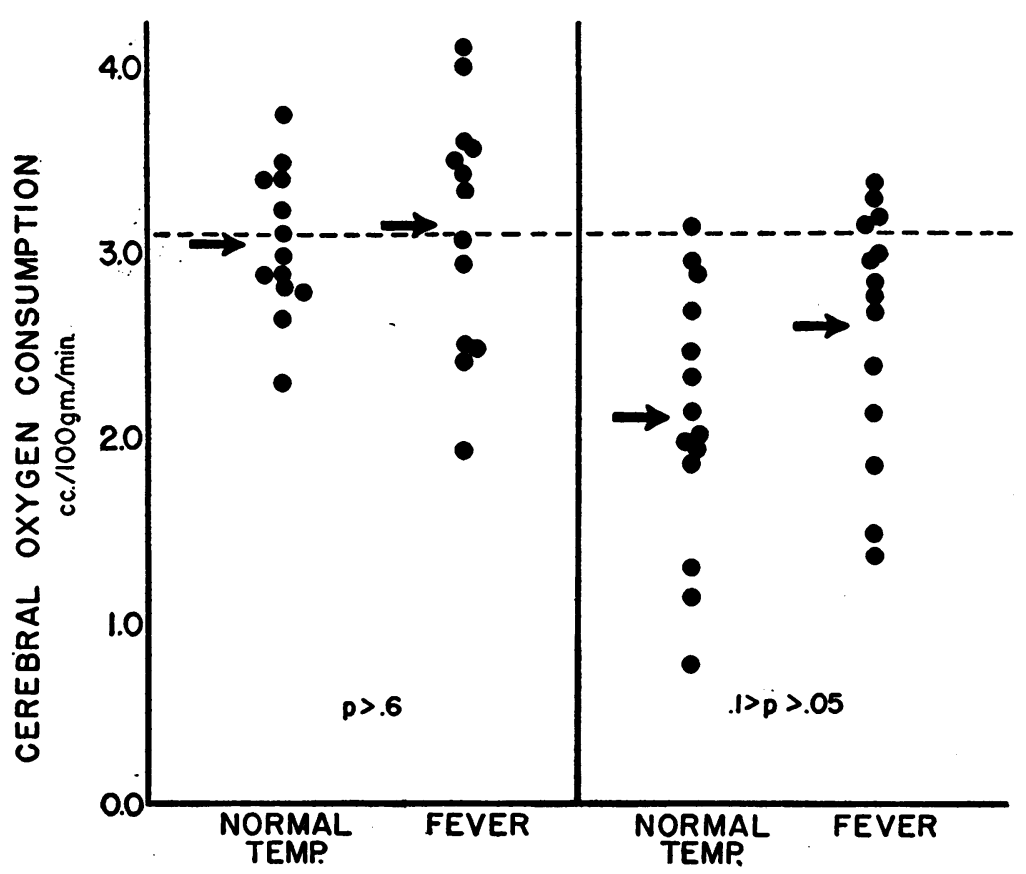

Fig. 3. Values for Cerebral Oxygen Consumption Obtained in the Individual Patients

The arrows indicate the mean value in each group. The broken line indicates the mean value in control subjects with normal temperature. 
ASYMPTOMATIC
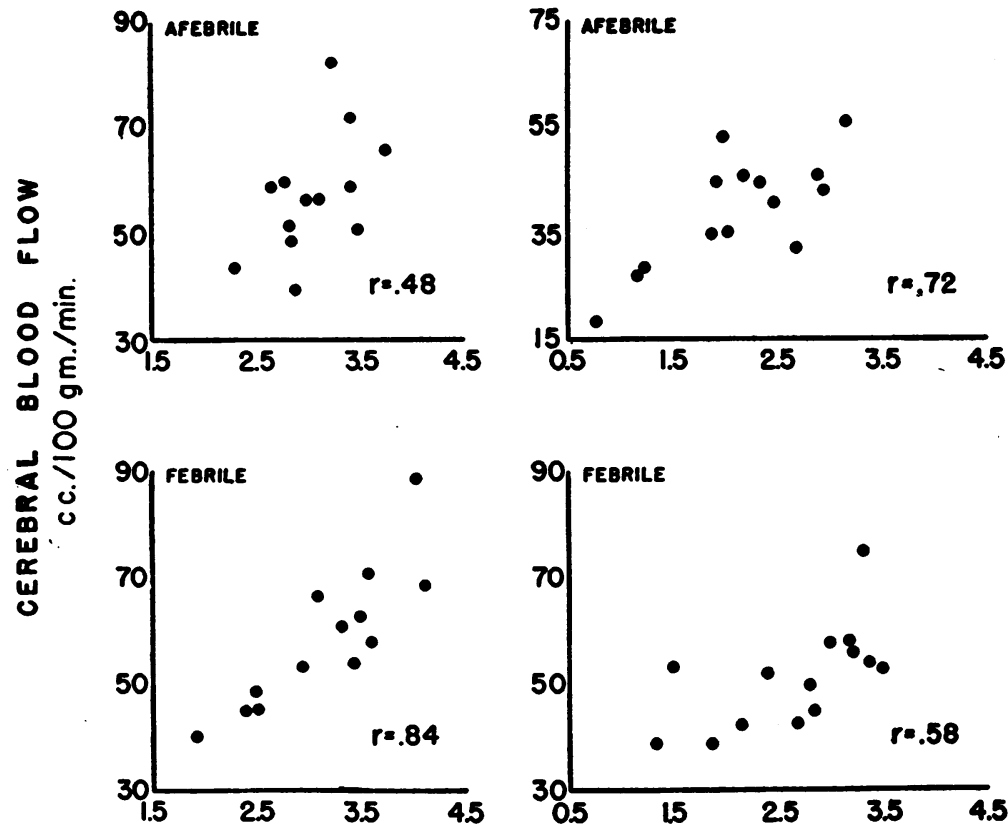

CEREBRAL OXYGEN CONSUMPTION c. $/ 100 \mathrm{gm} / \mathrm{min}$.

Fig. 4. Correlation Between Actual Values for Cerebral Blood Flow and Oxygen Consumption in Asymptomatic Neurosyphilis and Dementia Paralytica

Findings at normal body temperature and during fever are shown.

cardiac output, and in renal and hepatic blood flow. These changes occur even in the absence of fever. The relative importance, therefore, of temperature elevation versus pyrogenic material as factors producing the changes observed in our patients, cannot be assessed at present.

The question also arises whether the changes observed in the patients with asymptomatic neurosyphilis during fever are comparable to those of normal individuals. Five of the 13 patients with asymptomatic neurosyphilis were under 33 years of age and were known to have had syphilis for less than six years. These patients, furthermore, showed no evidence of hypertension or of vascular disease. In view of these facts and the prolonged period required for the development of the neurosyphilitic process, it seems likely that in these five patients the blood vessels and parenchyma of the brain were either normal or were involved only to a minimal degree. The observations on this group lead us to the tentative con- clusion that in normal individuals the cerebral blood flow and oxygen consumption change very little in pyrogen-induced fever.

The cardiac output is known to increase during fever produced by typhoid bacterial pyrogen (11) and it is probable that this also occurred in our patients. Since the mean $\mathrm{CBF}$ in the patients with asymptomatic neurosyphilis during fever did not change significantly, it is obvious that the brain in these patients did not obtain a share of the increase in cardiac output. There was, nevertheless, evidence that readjustments in the cerebral vessels did take place during fever. Dilatation of these vessels apparently occurred, since the cerebral blood flow remained unchanged despite a $23 \%$ fall in mean arterial pressure in these patients.

It seems likely that the increase in cerebral blood flow in the patients with dementia paralytica during fever was likewise the result of cerebral vascular dilatation. In these patients the vascu- 
lar changes were probably greater than those in the asymptomatic group, as suggested by the greater reduction in cerebral vascular resistance. It is apparent, therefore, that despite the structural alterations in the cerebral vessels in dementia paralytica, considerable changes in vascular caliber are still possible.

The mean oxygen consumption of the brain in the patients with asymptomatic neurosyphilis did not increase during fever, even though the metabolism of the body as a whole is known to increase by approximately 7 to $9 \%$ per degree Fahrenheit temperature elevation $(12,13)$. It is possible that the need of the brain for oxygen is not consistently increased during fever. This might account for the failure of the cerebral blood flow to increase. On the other hand, it is possible that the cerebral blood flow is the factor which limits the oxygen consumption. Since the CBF remained unchanged during fever, cerebral oxygen consumption could be increased only by a greater extraction of oxygen per unit volume of blood, with a consequent fall in oxygen tension.

The correlation during fever between $\mathrm{CBF}$ and $\mathrm{CMRO}_{2}$ in patients with dementia paralytica was not as good as that in asymptomatic neurosyphilis. This suggests that the presence of cerebral vascular disease alters the circulatory adjustments in fever. In spite of the damage produced by dementia paralytica the brain was still capable of increasing its metabolic processes during fever. Even the patients with the greatest reduction in $\mathrm{CMRO}_{2}$ and, therefore, presumably with the most marked cerebral damage, were capable of increasing their cerebral oxygen consumption.

The increased cerebral blood flow in dementia paralytica during fever may be a factor in the production of the beneficial effects of fever therapy in these individuals. Patients with asymptomatic neurosyphilis, however, show improvement in spinal fluid findings following fever therapy, despite the fact that their mean CBF is not increased. It is therefore probable that the therapeutic effects of fever in neurosyphilis are not brought about solely by changes in cerebral blood flow.

\section{SUMMARY}

1. Fever was induced by typhoid bacterial pyrogen or malaria in 13 patients with asymptomatic neurosyphilis and 14 patients with dementia para- lytica. The effects on the cerebral blood flow (CBF) and cerebral oxygen consumption (CM $\mathrm{RO}_{2}$ ) were determined.

2. Patients with asymptomatic neurosyphilis had a normal $\mathrm{CBF}$ and $\mathrm{CMRO}_{2}$ in the afebrile state, and showed only minimal changes during fever. Patients with dementia paralytica, however, showed $\mathrm{CBF}$ and $\mathrm{CMRO}_{2}$ values which were abnormally low in the afebrile state, but which increased on the average by $30 \%$ and $24 \%$, respectively, during fever.

3. It is apparent that the brain in asymptomatic neurosyphilis does not share in the increases in cardiac output and total body metabolism which are known to occur during fever. The tentative assumption is made that the normal brain has a response to fever similar to that of patients with asymptomatic neurosyphilis.

4. The possibility that the beneficial effects of fever therapy in dementia paralytica are in part related to the increase in cerebral blood flow is considered.

\section{ACKNOWLEDGMENT}

We are indebted to Misses Mary McPhaul, Fransetta Vinson, Ann Payne, Voncile Williams, and Eloise Cavin for their technical assistance.

\section{BIBLIOGRAPHY}

1. Himwich, H. E., Bowman, K. M., Fazekas, J. F., and Goldfarb, W., Temperature and brain metabolism. Am. J. M. Sc., 1940, 200, 347.

2. Looney, J. M., and Borkovic, E. J., The changes produced on the oxygen and carbon dioxide content of arterial and venous blood of the brain during diathermy therapy for general paresis. Am. J. Physiol., 1942, 136, 177.

3. Field, J., 2d, Fuhrman, F. A., and Martin, A. W., Effect of temperature on the oxygen consumption of brain tissue. J. Neurophysiol., 1944, 7, 117.

4. Dixon, K. C., The effect of rise in temperature on the carbohydrate catabolism of cerebral cortex. Biochem. J., 1936, 30, 1483.

5. Patterson, J. L., Jr., Heyman, A., and Nichols, F. T., Jr., Cerebral blood flow and oxygen consumption in neurosyphilis. J. Clin. Invest., 1950, 29, 1327.

6. Kety, S. S., and Schmidt, C. F., The nitrous oxide method for the quantitative determination of cerebral blood flow in man: theory, procedure and normal values. J. Clin. Invest., 1948, 27, 476.

7. Orcutt, F. S., and Waters, R. M., A method for the determination of cyclopropane, ethylene, and nitrous oxide in the blood with the Van Slyke-Neill manometric apparatus. J. Biol. Chem., 1937, 117, 509. 
8. Peters, J. P., and Van Slyke, D. D., Quantitative Clinical Chemistry, Vol. II, Methods. Williams \& Wilkins, Baltimore, 1943 (Emended Edition).

9. Bradley, S. E., Variations in hepatic blood flow in man during health and disease. New Eng. J. Med., 1949, 240, 456.

10. Bradley, S. E., Chasis, H., Goldring, W., and Smith, H. W., Hemodynamic alterations in normotensive and hypertensive subjects during the pyrogenic reaction. J. Clin. Invest., 1945, 24, 749.
11. Altschule, M. D., Freedberg, A. S., and McManus, M. J., Circulation and respiration during an episode of chill and fever in man. J. Clin. Invest., 1945, 24, 878.

12. Barr, D. P., Cecil, R. L., and DuBois, E. F., Clinical calorimetry. 32. Temperature regulation after the intravenous injection of proteose and typhoid vaccine. Arch. Int. Med., 1922, 29, 608.

13. Kopp, I., Metabolic rates in therapeutic fever. Am. J. M. Sc., 1935, 190, 491. 